\title{
Product Semantics in Design Research Practice
}

\author{
Jonas Sjöström ${ }^{1}$, Brian Donnellan ${ }^{2}$, and Markus Helfert ${ }^{3}$ \\ ${ }^{1}$ Department of Informatics \& Media and Department of Public Health and Caring Sciences, \\ Uppsala University, Sweden \\ jonas.sjostromaim.uu.se \\ ${ }^{2}$ National University of Ireland Maynooth Ireland and the Innovation Value Institute \\ brian.donnellan@nuim.ie \\ ${ }^{3}$ Dublin City University, Ireland \\ markus.helfert@computing.dcu.ie
}

\begin{abstract}
The concept of product semantics and its focus on meaning is used to interpret design research as design. It is argued that we may conceive of design research as design in two realms: The practical and the academic. In doing design research, there is a reciprocal shaping of artifacts: Better artifacts (contributions to practice) through appropriation of knowledge and methods from the academic realm, and better knowledge artifacts (contributions to academia) by drawing relevance and experiences of appropriation from the practical realm. We adopt a product semantics view to discuss research as design. Product semantics highlights the meaning of artifacts with respect to their (i) stakeholders, (ii) artifacts-in-use, (iii), artifacts-in-language, (iv) artifact lifecycle, and (v) ecology. Based on this interpretation, we propose activities that should characterize the practice of doing design research. Finally we provide an example of Design Research Practice in action.
\end{abstract}

Keywords: Design, research, practice, meaning, artifact.

\section{$1 \quad$ Introduction}

The IS field has paid an increased interest in design research (DR) over the last two decades. Design research is becoming recognized as equally important to behavioural information systems (IS) research [1,2]. Design is depicted as 'fundamental' to the IS discipline [3]. DR is manifested through special issues in leading journals, conference tracks, and dedicated conferences for design science research in IS. Purao et al [4] and Baskerville et al [5] provide a rich account of the development of DR in the IS field.

There is an on-going discussion about the norms that should govern DR, including both (i) what type of knowledge we can expect as a result of research, and (ii) how to accomplish rigor in the design process in order to substantiate claims. This corresponds to the process of research and the product (outcomes) of research. In design science research [1,2] knowledge outcome is defined as design science artifacts, i.e. constructs, models, methods and instantiations. Hevner et al [6] also propose that design science research may lead to new evaluation techniques. The idea 
of building design theory has been proposed [7,8], while action design research (ADR) suggests that the minimum requirement of the ADR approach is to formulate design principles that are applicable to design solutions for a class of problem [9]. The ambition in ADR initiatives should be to contribute to theory [9]. 'Scholarly contributions' are endorsed by major journals [10]. Orlikowski \& Iacono [11] identify five views of the IT artifact; (i) Tool view - functions and capabilities to perform tasks, substitute for labour, or improve productivity, (ii) Proxy view - perceptions as something to use and of value, (iii) Ensemble view - embedded relationship within social, organisational, and economic context, (iv) Computational view computational capabilities including processing and representational model and (v) Nominal view - abstract, non-specific, collective view. A very inclusive definition of IT artifacts is provided by Gill \& Hevner [12]: "IT artifacts are broadly defined as constructs (vocabulary and symbols), models (abstractions and representations), methods (algorithms and practices), and instantiations (implemented and prototype systems). More generally, artifacts can be viewed as the symbolic representation or physical instantiation of design concepts. Even within a discipline such as MIS, they are not necessarily limited to information systems. Rather, MIS artifacts include organizational designs, process designs, and other intentionally constructed entities relating to information systems."

Our interpretation of the discourse summarized above is that there are co-existing ideas about what the outcome of DR should be (models, methods, instantiations, constructs, new evaluation techniques, design principles, or design theory). Here, for the sake of our argument, we speak of design research as design of knowledge artifacts.

While this meta-theoretical development of DR in the IS field emerges, there has still been little effort to factor in other design traditions into the IS field. Although some IS research has promoted design thinking (e.g. [13,14]), it has not yet had considerable impact on the design research discourse in IS. Design thinking (e.g. $[15,16])$ and its notion of product semantics highlight stakeholders in design and their sense-making of artifacts. Product semantics stresses contextual approaches that focus on the meaning of artifacts in use and typically consider the design of affordances, constraints, feedback, coherence, learnability, multi-sensory redundancy, variability, robustness, and so forth as experienced by different stakeholders. Some recent IS publications incorporate concepts from design thinking (e.g. [10,12,17]). Interestingly, there has been little or no discussion about how DR can be conceived from a design perspective. Baskerville et al [10] show that lessons learned in design studies prove useful to further the meta-theoretical models in the IS field. Baskerville et al [10] employ the works of Cross [15] to distinguish conceptually between design and research in DR. In this paper, we make a similar contribution. We challenge the supposed distinction between design and research, claiming that design researchers in essence are designers of knowledge artifacts. A practice perspective is adopted to characterize design research as practice.

We employ ideas from product semantics to factor in fundamentals of design thinking into IS design research [16]. We explore design research as practice; and the multiple realms in which design research operates (section 2 ). The notion of product 
semantics, and the axiomaticity of meaning in design is elaborated (section 3 ), and used to elaborate on a case of design research practice as design (section 4). In section 5 , implications for design research practice are discussed.

\section{Realms of Design Research}

Sociologists have elaborated the concept of practice for a long time, and there is no 'unified' view of what it means [18]. Schatski [19] explains practice as "embodied materially mediated arrays of human activity centrally organized around shared practical understanding". The use of artifacts ("materially mediated") in action is recognized, while at the same time human action is acknowledged as part of a social context. Schatski's account of practice theory resonates well with the idea of a reciprocal shaping of action and structure, as proposed by Giddens [20]. Orlikowski [21] elaborates on Giddens' ideas through her notion of a duality of technology (as begin shaped by, and shaping, human action). In this paper, we adopt the view that design and appropriation of technology is strongly 'fused' with human action.

A key proposition in design research is that research results should be relevant and useful for practice [6]. At the same time, IS researchers are expected to contribute to the academic knowledge base (e.g. [7]). Goldkuhl [22] articulates a distinction between contributions to local practice (e.g. through a DR effort within a specific company) and contributions to general practice through re-usable knowledge (e.g. workshops and practitioner-oriented text books). Apart from contributing to both practice and academia, design researchers should draw rigor from the knowledge base and draw relevance from practice [6]. Design researchers thus operate in at least two different (but interdependent) social structures. We refer to these here as the practical realm and the academic realm (Figure 1). Each realm may be broken down into more specific practices, such as a single company in the practical realm or a specific sub-community (e.g. a journal or a conference) in the academic realm.

Figure 1 illustrates our view of design research as practice. The framework is clearly influenced by the IS design science research framework [1,6]. The realms of practice and academia can be recognized from Baskerville et al [10]. Our adaptation of the IS DSR framework is based on the notion that the DR practice interacts with other practices, either in the practical realm or in the academic realm. This corresponds with the ideals of relevant and useful research outputs from a practice point of view, while at the same time adhering to academic ideals. We acknowledge that ideals in practice and academia may partially overlap. In contrast to Hevner et al. [6], we seek to explicitly view the relation between the DR practice and the academic realm as action, governed by the ideals emerging in interplay with relevant stakeholder communities in the two realms. This way, ideals are situated rather than fixed, instead we highlight that any DR practice needs to be based on a process both to monitor and influence the discourse in the two realms. Research in IS and other disciplines is characterized by ideals that emerge through social interaction within the research community. An example of this is expressed by DeSanctis [23]: "Scholarly publication is a jointly constructed process, reflective of dialogue among researchers, reviewers, editors, and readers." Within a community, ideals emerge and evolve. 


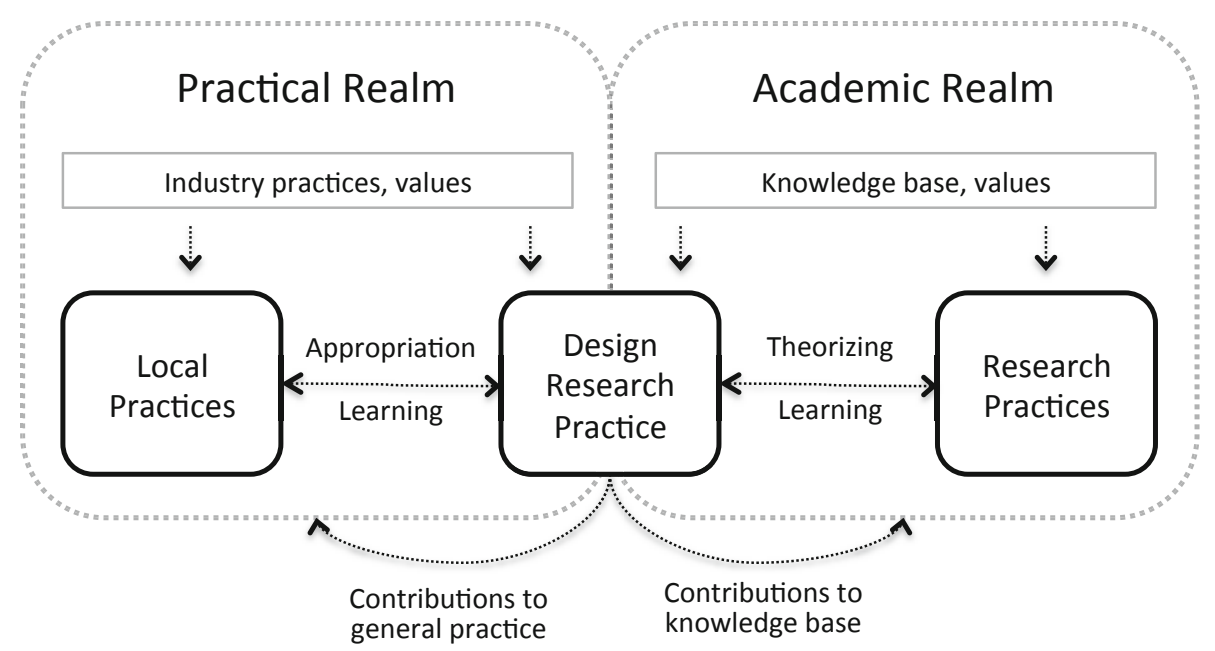

Fig. 1. The Multiple Realms of Design Research

Within the practical realm, we find local practices (e.g. public and commercial organizations). Practices in the academic realm may include research communities (such as AIS and ACM), governed by emergent value systems that are applied in the assessment of proposed contributions to the knowledge base. Practices in both realms may also be more narrowly defined, e.g. non-profit organizations in the practical realm or specific journals or communities in the academic realm.

In design research, learning occurs through moral inquiry [24]; i.e. an attempt to improve a situation. Evaluation is a core activity in DR, and there are several ideas about how to approach evaluation (what to evaluate, when to evaluate and how to evaluate). Arguably, the DSR approach [3] is biased towards a positivistic tradition of evaluation, while the ADR approach [9] emphasizes an interpretive approach to assessing artifacts when appropriated in practice. Similarly, Venable [25] suggests that we should distinguish between artificial versus naturalistic evaluation of artifacts. Artificial evaluation is conducted through experimental or analytical techniques (evaluating the artifact-as-such), while naturalistic evaluation concerns use qualities and emergent phenomena that cannot be assessed without an actual appropriation of the artifact in a 'real' empirical setting. Through appropriate evaluation efforts, design researchers can demonstrate the qualities of their artifacts. Gregor and Hevner [26] elaborate further on the relation between artificial and naturalistic evaluation and its relation to design science vs. behavioural science.

For design researchers, the ideal is to design artifacts that are highly valued, having an impact in both the practical realm and in the academic realm. An underlying DR assumption is that a DR practice will be able to design better artifacts by drawing from both realms. The practical realm ingrains design with relevance and allows us to perform naturalistic evaluations of artifacts, while the academic realm provides a knowledge base for design and evaluation, both with respect to the process and the product of research. Further, we are expected to contribute to both realms, and to communicate our results to multiple audiences [6]. 


\section{Adopting Product Semantics to Characterize Realms}

Krippendorff defines product semantics as "a vocabulary and methodology for designing artifacts in view of the meanings they could acquire for their users and the communities of their stakeholders". Although Krippendorff uses the term product semantics, we agree with Ehn [33] that it is in fact more appropriate to refer to Krippendorff's ideas as a pragmatic view of design. That being said, the notion of meaning and its impact on design is still at the core of product semantics. Krippendorff [16, p. 47] explains that meaning has a central role in design thinking: "Humans do not see and act on the physical qualities of things, but on what they mean to them." He refers to this as the 'axiomaticity of meaning' and argues: "There is no escape from the axiom. It states an undeniable truth that is so strong that one might as well embrace it fully for the strengths it provides for the design discourse. Without realizing its strength, designers are doomed to chase the ghosts of other discourses." [16 p. 50].

The notion of meaning is recognized in the social sciences. Krippendorff's notion of meaning resonates well with Peirce's semiosis, Bühler's symbolic interactionism, Polanyi's sense-reading and sense-giving, as well as Weick's sense-making, to mention a few. Polanyi [34 p. 181] states: "Both the way we endow our own utterances with meaning and our attribution of meaning to the utterances of others are acts of tacit knowing. They represent sense-giving and sense-reading within the structure of tacit knowing". As humans, we continually make sense of the world around us on the basis of our cumulated experiences. The interpretive view of the world is well recognized in IS research [35,36]. Krippendorff [16] emphasizes that designers need to seek a $2^{\text {nd }}$ order understanding - i.e. employ design methods that allow them to gain some degree of understanding of the meaning different stakeholders ascribe to artifacts. Krippendorff suggests that designers increase their chances to design successful artifacts by taking into account four different perspectives on how individuals attribute meaning to artifacts: (i) The meaning of artifacts in use, (ii) the meaning of artifacts in language, (iii) the meaning of a lifecycle of artifacts, and (iv) the meaning of an ecology of artifacts.

The success of an artifact depends on the meaning ascribed to them by stakeholders in each realm. We do not claim that every practice within each realm is identical, but that practices that belong to the same realm share similarities, and that there are notable differences between practices in the academic and the practical realm.

\section{IT-CMF: An Illustration of Design Research as Practice}

In this section, we introduce the design research practice Innovation Value Institute (IVI) and their IT-Capability Maturity Model (IT-CMF). We include the case to illustrate the explanatory power of product semantics in design research. IT-CMF is a high-level process capability maturity framework for managing the IT function within an organization. The framework identifies a number of critical IT processes, and describes an approach to designing maturity frameworks for each process. 
Table 1. Five aspects to consider in design

\begin{tabular}{|l|l|}
\hline Aspect & Description \\
\hline Stakeholders & $\begin{array}{l}\text { Individuals and/or organizations that are affected by the artifact(s); } \\
\text { or that have influence over the dissemination of artifact(s). }\end{array}$ \\
\hline $\begin{array}{l}\text { Artifacts in } \\
\text { use }\end{array}$ & $\begin{array}{l}\text { The way that stakeholders appropriate artifacts; and the way they } \\
\text { make sense of some them through their appropriation experiences. } \\
\text { Understood as the interplay between appropriation of artifacts } \\
\text { (materiality) and the social structure. }\end{array}$ \\
\hline $\begin{array}{l}\text { Artifacts in } \\
\text { language }\end{array}$ & $\begin{array}{l}\text { How stakeholders speak of artifacts. Especially adjectives that } \\
\text { signal how stakeholders assess the quality of artifact(s). }\end{array}$ \\
\hline $\begin{array}{l}\text { Lifecycle of } \\
\text { artifacts }\end{array}$ & $\begin{array}{l}\text { The way that stakeholders conceive of the 'status' of some } \\
\text { artifact(s) within the realm - the way it has been appropriated and } \\
\text { its projected future role within the realm. }\end{array}$ \\
\hline $\begin{array}{l}\text { Ecology of } \\
\text { artifacts }\end{array}$ & $\begin{array}{l}\text { Other artifacts in this realm (competing, supporting) that affect the } \\
\text { way that stakeholders attach meaning to the artifact(s) in focus. }\end{array}$ \\
\hline
\end{tabular}

The IT-CMF is a novel approach to managing IT resources due to its structured Design Science-based methodology [28]. The IT-CMF Content Development and Review Process is implemented by the IT-CMF development community of stakeholders in the Innovation Value Institute (www.ivi.ie). The IT-CMF is comprised by a set of interrelated artifacts. In terms of design science research [6] it consists of constructs, models, methods and instantiations. The IT-CMF constructs are basic definitions and templates to describe various IT managemens issues. ITCMF models include, among other things, critical process definitions and models to compare frameworks. IT-CMF methods include descriptions on how to assess maturity, and steps in the transition to new maturity levels. Finally, there are instantiations; software tools that are based on and facilitate the use of the IT-CMF constructs, models, and methods. In the case of the IT-CMF we see that both practical contributions and theoretical contributions are artifacts (products of design). Stakeholders from practice and academia interpret the idea of 'use', 'language', 'lifecycle' and 'ecology' differently.

In the remainder of this section, we appropriate Krippendorff's [16] notion of meaning to characterize IVI as a design research practice, and scrutinized the potential meanings of the IT-CMF using aspects of meaning derived from product semantics (as characterized in table 1).

\subsection{Stakeholders}

Krippendorff [16] emphasizes that "no artifact can be realized within a culture without being meaningful to those who can move it through its various definitions." Product semantics consequentially advocates a design process with a strong focus on - and participation of - stakeholders. 
In the practical realm, stakeholders may be understood as local practitioners, such as companies or government agencies. In addition, general practice may benefit from practical theory/design science artifacts/design principles to improve their organizations. Further, R\&D organizations benefit from commercialization of DR outcome/innovation/patents.

In the academic realm, stakeholders include (but are not limited to) individual researchers, the DR practice as such, and the institution(s) to which the DR belongs, funding agencies/organizations et cetera. However, stakeholders also include other researchers (reviewers, editors, other scholars).

The IVI community is comprised of university-based academic researchers and industry-based practitioner-researchers drawn from over 80 companies located throughout the world. Researchers collaborate with practitioners and subject matter experts within research teams to learn from key domain experts. Catering for constraints often faced when working in collaboration with practitioners, and individual expertise a design science oriented research process has emerged within the community. A key role of IVI - which we conceive of as a design research practice is to facilitate guided emergence [9] of the IT-CMF in the IVI web of stakeholders.

IT-CMF design is divided into four phases separated by stage reviews with key deliverables at each stage. At phase 1, details relating to the artifacts are consulted and expanded with input from group of key opinion leaders, subject matter experts, industry, and academic literature. At phase 2 comparisons are made with artefacts in industry frameworks and industry best practices. At phase 3 the artefacts are reviewed with 3-5 external organisations and key opinion leaders. At phase 4 the artefacts are exercised through field experiments in at least three organisations.

\subsection{The Meaning of Artifacts-in-Use}

In terms of DR outcomes in the practical realm, the aim of design is (arguably) to develop knowledge oriented towards change in a socio-material assemblage. Krippendorff [16] emphasizes the meaning of artifacts in use. The phenomena of 'design in use' has been discussed by IS researchers in terms of, for example, drift [38], tailoring [37], reinvention [31] and appropriation (e.g. [37,38]. There has been a lot of interest put into how artifacts, e.g. IT systems, are appropriated in the practical realm. In addition, appropriation is a pre-requisite to 'naturalistic' evaluation [25] of our artifacts.

The phased design approach in IVI leads to a step-wise refinement of artifacts, from ideas to actual appropriation by local practices. IT-CMF has also been appropriated by several of the industrial stakeholders, in some cases through researcher-practitioner collaboration based on action research, in some cases using other evaluation techniques appropriated at different implementation stages [29].

Experiences from the development of the IT-CMF show that the everyday engagement in an information process "shows unexpected consequences: events, behaviors, and features of systems and the people who use them fall outside the scope of the original specifications" [32, p 44]. Use patterns are irregular, often contradictory, untidy, and subject to approximation. Current design science literature 
tends to separate the design of the artifact from the teleological goal of the artifact (i.e. its use in on-going but changing information processes) while at the same time declaring that these two aspects are inseparable. Our position is that it is impossible to completely specify an information process ex ante. The information manipulated by an actor engaged with an information system is intended to be consumed by human actors in some fashion, rather than to satisfy the whims of a technology or an a priori design.

In a similar manner, knowledge artifacts are actually evaluated based on their 'appropriation' in the academic realm. Local and international workshops, special interest communities, and conferences provide opportunities to 'prototype' artifacts in the academic realm. However, true 'appropriation' of knowledge artifacts will only occur when the artifacts are adopted in new design situations, by their own DR practice or by other researchers who incorporate knowledge artifacts in their own studies. By appropriation in new situations, we will be able to perform 'naturalistic' evaluations of these knowledge artifacts in a new design setting. A DR practice can exploit this opportunity, as a means to evaluate and further improve their work.

\subsection{The Meaning of Artifacts-in-Language}

Krippendorff claims that an important role of a designer is to interpret the discourse among stakeholders, stating "The fate of all artifacts is decided in language". Communication between designers and other stakeholders is a core issue. Several approaches to improving sense-making have been proposed over the years, such as various types of user-centered approaches, e.g. prototyping in interaction design, and arenas and concepts for customer-developer interaction in agile development. They all share the idea that designers need to promote communication and learning between stakeholders. In product semantics [16], the importance of language is manifested in several ways, e.g. through user-centered design processes and through questionnaires that are used to assess how stakeholders perceive the artifact and its potential usefulness during the design process.

The IT-CMF stage reviews provide a communicative arena where stakeholders assess artifacts-in-use and new design proposals. In addition, the academic arena is considered important to scrutinize artifacts in terms of (for example) conceptual coherence, rigor and theoretical justification. By exposing 'scholarly adapted' representations of the IT-CMF - i.e. research papers that address certain aspects of the framework and the design research process - peers from the academic community provide constructive criticism that support the development of artifacts further.

The peer review mechanism provides a feedback loop between the practical and the academic realm, where the practical realm feeds design researchers with relevance and appropriation experiences, while the academic realm supports assessment of 'scholarly' oriented qualities of artifacts. Thus, different representations of the ITCMF artifacts reside in multiple discourses, and design researchers shift focus between these. A challenge for an institute like IVI is to strategically appropriate the publication process as a type of 'scholarly evaluation' of artifacts. Clearly, there are career incentives for academic scholars to relate to academic norms (otherwise they 
do not get published). Other stakeholders will not support the scholarly work if there is no evident value for their industrial practices.

In the academic realm, the difference between 'use of artifacts' and 'artifacts in language' becomes somewhat fuzzy. If the artifact is a concept, we may conceive of it as being appropriated when it becomes part of a discourse. Indeed, Krippendorff [16] characterizes discourse as a type of complex and human-centered artifact. Use of knowledge artifacts may consist of how we interpret those artifacts, represent them in our own discourses and appropriate them into our own research. However, researchers attempt to sensitize themselves to how their knowledge artifacts are interpreted and assessed by other researchers in the scholarly discourse (e.g. what reviewers express and how their work is cited). This is a type of feedback, both with respect to the way knowledge artifacts are appropriated and how they are framed in language by others. Academic ideals, especially in DR, promote communication to different audiences (e.g. [6]). We emphasize here that the way others speak of our artifacts (both in the practical and the academic realm) is valuable for improvement of knowledge artifacts.

\subsection{The Meaning of a Lifecycle of Artifacts}

Krippendorff 's emphasis on the lifecycle perspective suggests that designers should focus on the "before" the project, the "procurement" process of aligning actants in a design project and how the object of a design becomes this specific design object. This view has been discussed in the DR discourse. The socio-material notion of emergence resonates well with the idea of mutability of artifacts ([7], [12]). Although artifact mutability has been elaborated ([10]; [7]), it is still peripheral in the DR discourse. The idea of mutability, however, is clearly a basis for Gill \& Hevner's [12] utility-fitness model, which proposes that we focus on (i) the ability of an artifact to prove useful in a specific situation, and (ii) that the artifact proves useful over time in various situations in its socio-material context, (iii) in competition with other artifacts that address the same class of problems. Gill \& Hevner's model thus introduces a perspective on the value of artifacts that is similar to Krippendorff's [16] emphasis on understanding the meaning of artifacts from a lifecycle perspective as well as an ecological perspective (next section).

The lifecycle perspective may also prove useful for the design of 'knowledge artifacts'. If the ultimate goal of DR is to make a difference, it is imperative to consider artifacts from a lifecycle perspective. This can be done both with respect to the practical realm and the academic realm.

Figure 2 illustrates our view on the emergent contributions that DR practices can make into the two realms. In the practical realm, artifacts 'advance' in steps, such as formative design workshops with prototypes, appropriation into local practices and subsequent evaluation of the results, dissemination to general practice, and sometimes 'success' in general practice. In those cases, artifacts become an integrated part of the ecology of artifacts (e.g. the relational database model and its implementations in database management technologies). In the academic realm, ideas are initially discussed within the design practice or in smaller workshops in institutions or networks. After that, results are exposed through workshops and conferences, followed by attempts to publish in journals. Finally, the artifacts may be adopted, cited, and part of the cumulative research within the academic realm. 


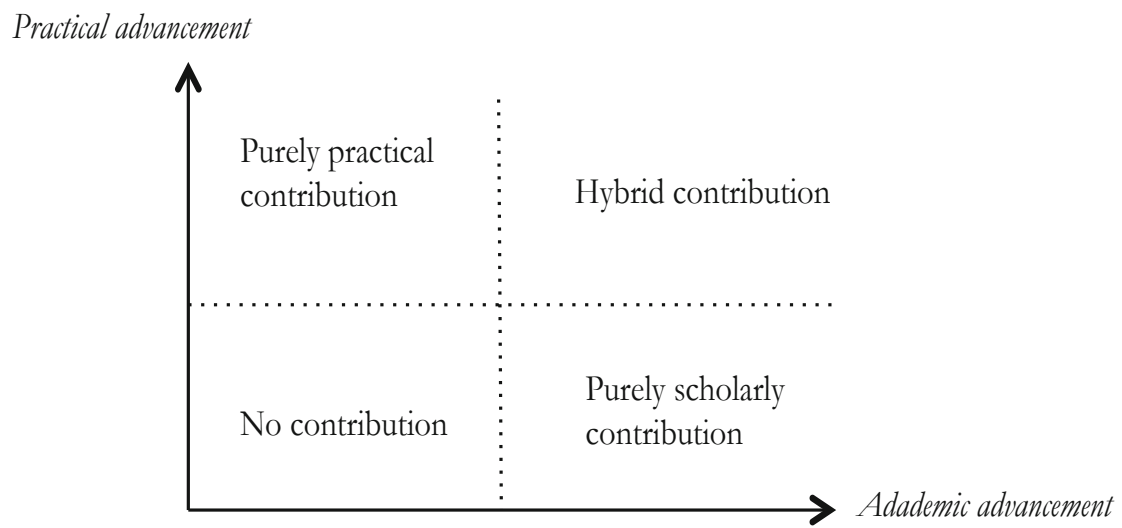

Fig. 2. Artifact advancement in the two realms of DR

In practice, we attempt to build IT artifacts that are mutable to fit into the emerging social world. In academia, we attempt to generalize artifacts beyond limited contexts and specific technologies. The lifecycle perspective is also highly political: A designer (design researcher) needs to plan ahead and manage the needs of multiple stakeholders to promote continued resources for design and future success of an artifact.

At some point, advancements in both realms may become obsolete or fade away due to a changed world or new artifacts that outcompete the old ones.

The establishment of IVI is the result of a shared interest among stakeholders to develop artifacts that are valuable in a long-term perspective. Various versions of the IT-CMF are currently appropriated (to different degrees) in companies in the IVI community. Experiences from cases of situated appropriation feed re-design of the framework on the generic level. Revised versions of IT-CMF may be adopted by the local practices. The idea is that the DR practice supports improvements - thus the survival - of the IT-CMF over time.

The lifecycle of artifacts in the two realms may be out of phase. In the IVI context, the main progress has taken place in the practical realm, rather than in the academic realm. There is not necessarily a correlation between success in the two realms. However, a fundamental idea in design research appears to be that the interplay between practice and academia promotes the quality of artifacts. Following this idea, artifacts that are reviewed in accordance with ideals from both realms should be more likely to be valuable in a long-term perspective.

It is not unlikely that a heavily used artifact in the practical realm will be subject to more scholarly attention. Conversely, artifacts that are successful in academia, such as balanced scorecards [27], may lead to practical design solutions.

\subsection{The Meaning of an Ecology of Artifacts}

Krippendorff's [16] perspective on ecology, influenced by Bateson [30], proposes that designers need to recognize the meaning of an ecology of artifacts, stating that 
"Designers who can handle the ecological meaning of their proposals have a better chance of keeping their designs alive." People attach meaning to artifacts in relation to other artifacts. This relationship can span a number of dimensions e.g. cooperation, competition, interdependence, reproduction and retirement of artifacts in specific contexts. An example from a technical perspective is that artifacts depend on infrastructure. There are other relations in an ecology of artifacts, such as competing artifacts, or artifacts that 'thrive' through the existence of other artifacts [12]. From the perspective of technical stakeholders, the ecology looks different. IT strategists / architects would try to see how a specific IT artifact 'fits in' and contributes to an existing IT infrastructure. When it comes to models and methods, those would be assessed against the current methods and models in use in a particular organization.

In the academic realm, our artifacts are similarly connected to an ecology of knowledge artifacts. We are expected to draw from the knowledge base e.g. [6] and strive for a cumulative tradition [7]. When designing a new artifact (i.e. producing knowledge) designers/researchers need to build upon existing artifacts and clearly relate their new artifacts to the knowledge base. Further, for design researchers, there is a need to build artifacts targeting the practical realm in order to meet the ideals of relevance and utility.

The IT-CMF is comprised of different but inter-dependant critical capabilities that grow and develop in relation to each to each other. It is a system of artifacts in its own. However, for its stakeholders, it will also be made sense of in relation to their existing base of artifacts (and other available governance-related concepts). For instance, several companies in the IVI community are using parts of the IT-CMF, adapted to fit in with other governance frameworks such as ITIL. The second phase in the IVI design process provides a structure to reflect about the 'ecology' and its implications for the continued design of the IT-CMF. For design research practice, this implies a need to identify activities to support the evolution of design artifacts over time (lifecycle perspective) to make them part of the 'ecology' of artifacts.

The qualities of an artifact alone cannot explain its survival in a competitive world. Organizational development and decision-making is a political process. Thus, any artifact that is not supported actively by stakeholders become a "prey" to other artifacts - "predators" that are more extensively promoted, e.g. for commercial reasons. When it comes to academic promotion of ideas, publications in high impact journals increase the readership as well as the likelihood of citations. Furthermore, researchers may engage in various activities to expose their ideas to others in academia. Commercial organizations have strong incentives to promote their products. An implication for a DR practice like IVI is that they also need to reflect about the promotion of their artifacts, either through commercial strategies or through other mechanisms. Consequently, any DR practice aiming for innovation needs to actively monitor the appropriate 'ecology' of artifacts and promote their own artifacts within this ecology.

\section{Concluding Discussion}

The product semantic perspective provides a lens to make sense of design research practice, as illustrated by the IT-CMF case. The development of the IT-CMF 
illustrates a situation where both practical contributions and theoretical contributions are artifacts. Although stakeholders from industry and academia may interpret the idea of 'use', 'language', 'lifecycle' and 'ecology' differently, nevertheless the community is able to obtain a second order understanding of stakeholder views within the two realms, and promote the success of artifacts in both realms.

We have addressed a number of issues faced in design research practice, issues not previously in focus in the DR discourse. The outcome of DR practice should be valuable for other practices that are governed by their own set of values and history (knowledge base). In contrast to previous research we do not presume that any specific values - such as rigor and relevance - are in focus. We conclude that an important activity in a DR practice is to continually investigate the ideals that need be met in both realms, and also to try to affect those ideals. We recognize the emergent characteristics of the realms, and the reciprocal shaping of values between any practice and its environment. Even though some values may be rather stable over time (such as relevance and rigor in IS research), they are indeed dynamic and contextspecific. A conclusion from this is that continuous interpretation and active participation in the discourse on ideals are important activities in DR practice. The way that we conduct research and succeed in publishing reinforces and/or weakens ideals in the research community.

The idea of emergent and reciprocally shaped ideals may prove useful in further conceptualizing DR evaluation. Evaluation takes place formatively to improve design, but also as a means to demonstrate artifact qualities to stakeholders. As stated by Krippendorff [16]: "No artifact can be realized within a culture without being meaningful to those who can move it through its various definitions". Evaluation needs to be understood from the political perspective as well as the formative perspective. Exposure of an artifact, whether in the practical realm or in the academic realm, is multi-functional. As a design researcher, academic publication as well as appropriation of artifacts in practice, needs to be conceived of as interwoven yet analytically distinguishable activities. The very reason to operate as design researchers is based on the assumption that the quality of the emerging compound of artifacts is increased through the interplay between evaluation in the academic realm and evaluation in the practical realm. We conceive of the exposure of an artifact into either realm as a form of 'naturalistic evaluation'. In addition to this, DR practices may conduct artificial evaluation 'in-house', e.g. through qualified discourse within the DR team and simulations. This leads us to a more elaborate concept of evaluation in design research, which occurs in many forms: (1) artificial evaluation; through evaluation measures taking place within the DR practice, (2) naturalistic evaluation; through appropriation of ideas in local practices, and through feedback from those practices to the DR practice, and (3) scholarly evaluation; through the discourse that takes place within the academic realm through peer-review and other forms of interaction between researchers.

The proposed product semantics perspective on DR practice harmonizes with 'the practice turn' in organizational research. By addressing DR as design, we recognize the politics and value-ladenness of design research. As stated by Gherardi [18, p. 124]: “[..] practice as epistemology articulates knowledge in and about 
organizing as practical accomplishment, rather than as a transcendental account of a decontextualized reality done by a genderless and disembodied researcher."

Acknowledgements. This work has been partially funded by the Swedish Research School of Management and Information Technology (MIT).

\section{References}

1. Hevner, A.R.: A three-cycle view of design science research. Scandinavian Journal of Information Systems 19(2), 87-92 (2007)

2. Iivari, J.: A paradigmatic analysis of information systems as a design science. Scandinavian Journal of Information Systems 19(2), 39-64 (2007)

3. March, S.T., Smith, G.F.: Design and natural-science research on information technology. Decision Support Systems 15(4), 251-266 (1995)

4. Purao, S., Baldwin, C.Y., Hevner, A., Story, V.C., Pries-Heje, J., Smith, B., Zhu, Y.: The Sciences of Design: Observations on an Emerging Field. Working paper. Harvard Business School (2008)

5. Baskerville, R., Lyytinen, K., Sambamurthy, V., Straub, D.: A response to the designoriented information systems research memorandum. European Journal of Information Systems 20, 11-15 (2011a)

6. Hevner, A.R., March, S.T., Park, J., Ram, S.: Design Science in Information Systems Research. MIS Quarterly 1(28), 75-105 (2004)

7. Gregor, S., Jones, D.: The Anatomy of a Design Theory. Journal of the Association for Information Systems 8(5), 312-335 (2007)

8. Kuechler, B., Vaishnavi, V.: On theory development in design science research: anatomy of a research project. European Journal of Information Systems 17(5), 489-504 (2008)

9. Sein, M.K., Henfridsson, O., Purao, S., Rossi, M., Lindgren, R.: Action Design Research. MIS Quarterly 35(1), 37-56 (2011)

10. Baskerville, R., Kaul, M., Storey, V.: Unpacking the Duality of Design Science. In: ICIS 2011 Proceedings. Paper 10 (2011b)

11. Orlikowski, W., Iacono, C.: Research commentary: desperately seeking the "IT" in IT research-A call to theorizing the IT artifact. Information Systems Research 12(2), 121-134 (2001)

12. Gill, T.G., Hevner, A.R.: A Fitness-Utility Model for Design Science Research. In: Jain, H., Sinha, A.P., Vitharana, P. (eds.) DESRIST 2011. LNCS, vol. 6629, pp. 237-252. Springer, Heidelberg (2011)

13. Winograd, T., Flores, F.: Understanding Computers and Cognition: A New Foundation for Design. Ablex, Norwood (1986)

14. Ehn, P.: The Art and Science of Designing Computer Artefacts. Scandinavian Journal of Information Systems 1(1), Art. 3 (1989)

15. Cross, N.: Designerly ways of knowing: Design discipline versus de sign science. Design Issues 17(3), 49-55 (2001)

16. Krippendorff, K.: The Semantic Turn: A New Foundation for Design. CRC Press (2006)

17. Sjöström, J.: Designing Information System - A pragmatic account. Doctoral Dissertation, Uppsala University, Sweden (2010) ISBN 978-91-506-2149-5

18. Gherardi, S.: Introduction: The Critical Power of the 'Practice Lens'. Management Learning 40(2), 115-128 (2009) 
19. Schatski, T.R.: Introduction: Practice theory. In: Schatzki, T.R., Knorr, C.K., von Savigny, E. (eds.) The Practice Turn in Contemporary Theory. Routledge, London (2001)

20. Giddens, A.: The Constitution of Society: Outline of the Theory of Structuration. Polity, Cambridge (1984)

21. Orlikowski, W.: The duality of technology: Rethinking the concept of technology in organizations. Organization Science 3(3), 398-427 (1992)

22. Goldkuhl, G.: Design theories in information systems-a need for multi- grounding. Journal of Information Technology Theory and Application 6(2), 59-72 (2004)

23. DeSanctis, G.: The Social Life of Information Systems Research - A Response to Benbasat and Zmud's Call for Returning to the IT Artifact. Journal of the Association for Information Systems 4(7), 360-376 (2003)

24. Dewey, J.: Logic: The theory of inquiry. Henry Holt and Company, New York (1938)

25. Venable, J.: A framework for Design Science research activities. In: Khosrow-Pour, M. (ed.) 2006 Information Resources Management Association International Conference, May 21, pp. 184-187. Idea Group Publishing, Washington, DC (2006)

26. Gregor, S., Hevner, A.: Positioning and Presenting Design Science Research for Maximum Impact. Paper Currently Under Journal Review (in press)

27. Kaplan, R.S., Norton, D.P.: The Balanced Scorecard: measures that drive performance. Harvard Business Review, 71-80 (January- February 1992)

28. Helfert, M., Costello, G., Donnellan, B.: The Case for Design Science Utility -Evaluation of Design Science Artefacts within the IT Capability Maturity Framework. In: Artifact Design and Workplace Intervention (ADWI) Workshop, Barcelona, June 10 (2012)

29. Donnellan, B., Helfert, M.: The IT-CMF: A Practical Application of Design Science. In: Winter, R., Zhao, J.L., Aier, S. (eds.) DESRIST 2010. LNCS, vol. 6105, pp. 550-553. Springer, Heidelberg (2010)

30. Bateson, G.: Steps to an Ecology of Mind: Collected Essays in Anthropology, Psychiatry, Evolution, and Epistemology. University of Chicago Press (1972) ISBN 0-226-03905-6

31. Orlikowski, W.: Using technology and constituting structures: a practice lens for studying technology in organizations. Organization Science 11(4), 404-428 (2000)

32. Ågerfalk, P.J.: Investigating Actability Dimensions: A language/action perspective on criteria for information systems evaluation. Interacting with Computers 16(5), 957-988 (2004)

33. Ehn, P.: Review of The Semantic Turn: A New Foundation for Design. Artifact 1(1), 59-63 (2007)

34. Polanyi, M.: The Tacit Dimension. Doubleday \& Co. Inc., New York (1966)

35. Walsham, G.: The emergence of interpretivism in IS research. Information Systems Research 6(4), 376-394 (1995)

36. Klein, H.K., Myers, M.D.: A set of principles for conducting and evaluating interpretive field studies in information systems. MIS Quarterly 23(1), 67-93 (1999)

37. De Sanctis, G., Poole, M.S.: Capturing the complexity in advanced technology use: adaptive structuration theory. Organization Science 5(2), 121-147 (1994)

38. Trigg, R., Bødker, S.: From implementation to design: Tailoring and the emergence of systematization. In: Proceedings CSCW 1994, Chapel Hill, NC (1994) 